\title{
The Accomplishments of Lithium Target and Test Facility Validation Activities in the IFMIF/EVEDA Phase
}

\author{
F. Arbeiter, P. Favuzza, F. Gröschel, R. Heidinger, A. Ibarra, J. Knaster, T. Kanemura, H. Kondo, V.
} Massaut, F.S. Nitti, G. Micciche, S. O’hira, D. Rapisarda, E. Wakai, T. Yokomine
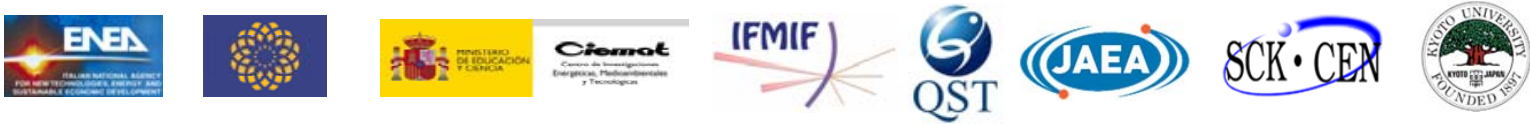

During the Engineering Validation and Engineering Design Activities (EVEDA) phase of the International Fusion Materials Irradiation Facility (IFMIF), major elements of the Lithium Target Facility (the neutron source) and the Test Facility (implementing the irradiation experiments) were prototyped and tested. These works were successfully concluded in the frame of the Japanese and European Broader approach activities between 2007 - 20015.

The validation activities included basic research (SSTT, corrosion), components (irradiation modules) and large scale facilities (lithium and helium loops). The results were fed back to the EVEDA design process and support the ongoing design activities towards an IFMIF plant to be realized timely, as necessary element of the fusion roadmaps.

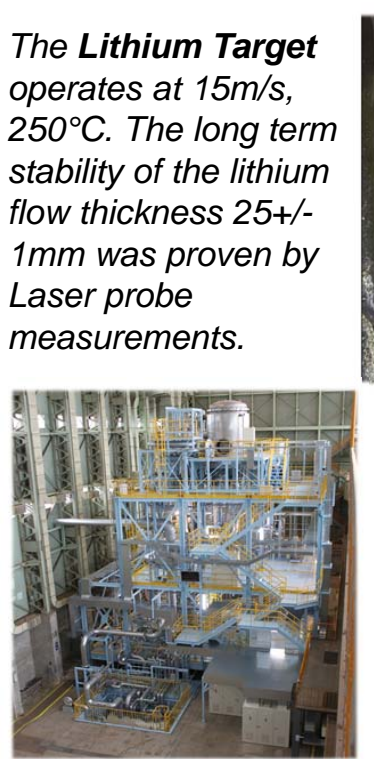

The Lithium Loop supplies a constant flow of $\mathrm{Li}$ to the target. The ELTL loop operated 519 days, startup and operation scenarios as well as Li purity measurements were performed.

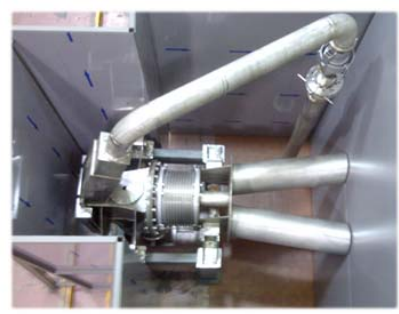

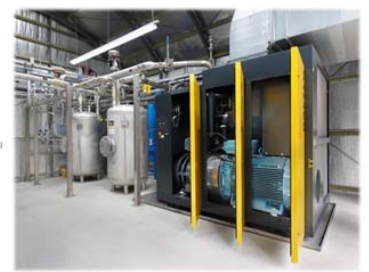
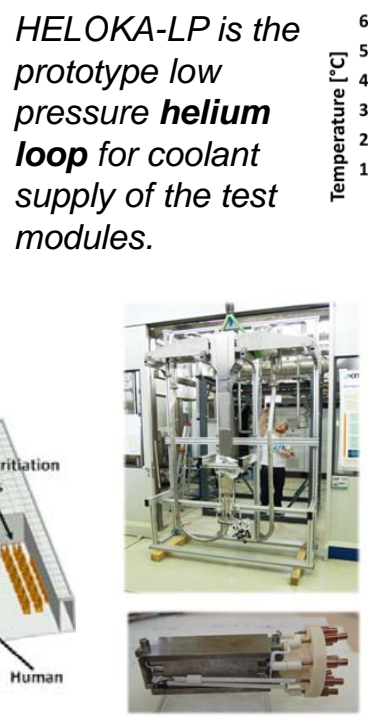

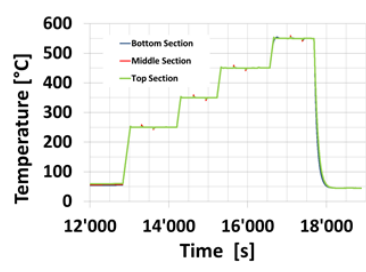

Prototypes of two High Flux Test Module versions were built. The irradiation temperature range (HFTM-V: $250-550^{\circ} \mathrm{C}$, HFTM-H: up to $1000^{\circ} \mathrm{C}$ ) and temperature homogeneity was demonstrated.

The IFMIF plant overview

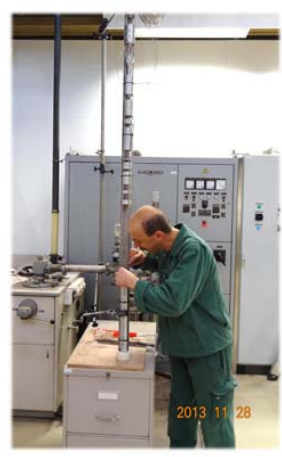

Remote handling operations were validated for a 1:1 Target Assembly mockup.
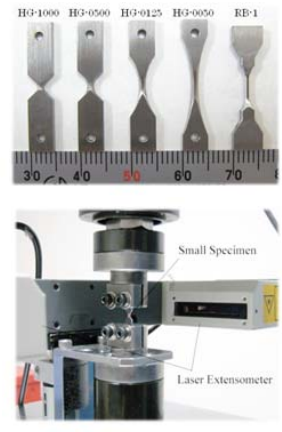

The Smal Specimen Test Technique is essential for the IFMIF mission. Specimen shapes, test setups and data analysis were further developed.
An irradiation in the BR2 reactor served to test the irradiation capsules, fission chambers and Cherenkov fiber optics for the characterization of the IFMIF source.

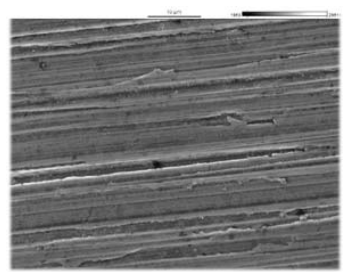

Li-corrosion tests of RAFM steels under relevant conditions $(15 \mathrm{~m} / \mathrm{s},<30$ wppm N, $330^{\circ} \mathrm{C}$ ) showed erosion $<0.3 \mu \mathrm{m} /$ year 